\title{
PRIME LAB: A DEDICATED AMS FACILITY AT PURDUE UNIVERSITY
}

\author{
DAVID ELMORE, F. A. RICKEY, P. C. SIMMS, M. E. LIPSCHUTZ1' K. A. MUELLER and \\ T. E. MILLER
}

Department of Physics, Purdue University, West Lafayette, Indiana 47907 USA

\begin{abstract}
A new facility for accelerator mass spectrometry has been established at Purdue University. First results have been obtained for ${ }^{10} \mathrm{Be}$ and ${ }^{36} \mathrm{Cl}$, and several internal research projects have been initiated. Plans are to become a national AMS facility to serve the Earth and planetary science communities for the full range of cosmogenic radionuclides.
\end{abstract}

\section{INTRODUCTION}

The School of Science at Purdue University has dedicated its FN tandem Van de Graaff accelerator to the Purdue Rare Isotope Measurement Laboratory (PRIME Lab) with plans to become a national facility for accelerator mass spectrometry (AMS). We have completed construction of the initial phase with the addition of a new ion source/injector system, a new beam line and an upgrade of the tandem. For a start, we plan to measure the cosmogenic radionuclides ${ }^{10} \mathrm{Be},{ }^{36} \mathrm{Cl}$, and ${ }^{26} \mathrm{Al}$ at a few percent precision in geologic and planetary materials. Later, we will add capability for the radionuclides, ${ }^{14} \mathrm{C},{ }^{41} \mathrm{Ca}$ and ${ }^{129} \mathrm{I}$, improve precision to better than $1 \%$, and extend applications to the materials and biological sciences.

Although the laboratory will continue a small nuclear physics program, AMS will become the prime activity on the accelerator, using as much as $90 \%$ of the beam time. The model FN tandem accelerator, made by High Voltage Engineering Corporation, is well suited for measuring the full range of AMS isotopes, and is in good operating condition.

Plans for the facility call for the concurrent buildup of a Purdue-based research program, an outside user base and analytical capability through instrumentation upgrades. The first research will center on the use of cosmogenic radionuclides in Earth and planetary sciences. Applications underway include surface exposure dating using buildup of cosmic-ray produced radionuclides in rocks, groundwater dating and tracing, meteorite population variations as a function of fall location and terrestrial age, depth profiles in meteorites, and soil formation and erosion.

\section{FACILITY DESCRIPTION}

The goals for the next $1-2$ years are to measure ${ }^{10} \mathrm{Be}$ and ${ }^{36} \mathrm{Cl}$ at $3-5 \%$ precision and a relatively low capacity of a few hundred samples per year. We are making the effort to construct a high-quality system from the start to reduce future maintenance costs and avoid having to rebuild components later. A schematic diagram of the facility is shown in Figure 1.

The PRIME Lab building is located underground next to the Physics building, which is centrally located on campus. It has 31,000 square feet of floor space on two stories with 14 offices, 16 laboratories and spacious accelerator and target rooms.

We purchased a high-intensity cesium sputter ion source that is identical to the ion source used at the Woods Hole Oceanographic Institution radiocarbon facility. A major concern for this type of ion source has been the intensity of the isobar, ${ }^{36} \mathrm{~S}$, produced from $\mathrm{AgCl}$ samples. By using a sam-

${ }^{1}$ Department of Chemistry, Purdue University 


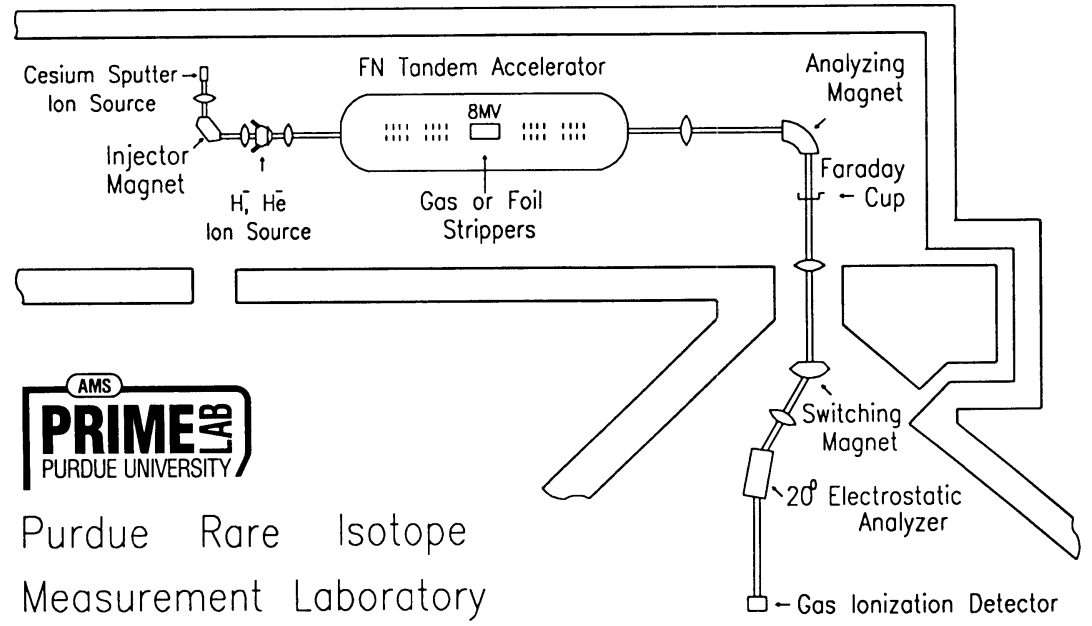

Fig. 1. Schematic diagram of AMS facility at PRIME Lab. Lens-shaped symbols represent electrostatic Einzel lenses (before the accelerator) and magnetic quadrupole doublets (after the accelerator).

ple holder of $\mathrm{AgBr}$ baked to $300^{\circ} \mathrm{C}$ before loading the $\mathrm{AgCl}$ samples, we reduced the ${ }^{36} \mathrm{~S}$ counting rates to below 100 counts $\mathrm{sec}^{-1}$. This rate is low enough to cause no interference at the ${ }^{36} \mathrm{Cl} / \mathrm{Cl}=$ $10^{-15}$ level with our detector system at energies of 50-60 MeV. Samples of only $500 \mu \mathrm{g}$ of chloride give stable currents for over $4 \mathrm{~h}$. We are currently inserting samples individually, but plan to build a multiple sample changer of our own design.

The insulated injector stand built at Purdue provides a $95 \mathrm{keV}$ beam for mass analysis in the $90^{\circ}$ injector magnet on long-term loan from Rutgers University. This high injection energy allows good transmission efficiency through the magnet, helps remove interfering tails from the beam and provides good coupling of the beam into the accelerator. Power supplies for the ion source are at platform potential; this requires an isolation transformer and insulated control rods for user adjustment.

We conditioned the model $\mathrm{FN}$ tandem accelerator up to $8 \mathrm{MV}$, but a sparking problem has recently limited use to 6-7 MV. A new charging belt and replacement of the charging screens with shim stock has greatly improved terminal stability. New cryopumps at each end of the accelerator have greatly improved accelerator vacuum. The reinstallation of the gridded lens at the entrance to the accelerator has improved the accelerator transmission efficiency to $12 \%$ for chlorine in charge state 7.

The new AMS beam line on the right-hand $30^{\circ}$ port of the switching magnet contains a magnetic quadrupole doublet, a $20^{\circ}$ electrostatic analyzer with ion pump, an aperture ladder and a Faraday cup. The electrostatic analyzer bends in the horizontal direction and does not pass any detectable isotopic interference during ${ }^{10} \mathrm{Be}$ and ${ }^{36} \mathrm{Cl}$ measurements.

The multi-anode gas ionization detector is patterned after the detector built at Rochester, except that it loads into its vacuum chamber from the side and uses printed circuit boards for interior electrodes. A cylindrically symmetric foil plus gas absorber cell is located at the entrance for stopping ${ }^{10} \mathrm{~B}$ during ${ }^{10} \mathrm{Be}$ analysis. The performance for ${ }^{36} \mathrm{Cl}$ detection is excellent: with 2500 counts $\mathrm{sec}^{-1}$ of ${ }^{36} \mathrm{~S}$ and no ${ }^{36} \mathrm{Cl}$ incident on the detector, the background inside gates set for ${ }^{36} \mathrm{Cl}$ is less than 1 count $\min ^{-1}$. 
In the first phase of PRIME Lab operation, we are obtaining isotope ratios by cycling the magnetic fields in the two $90^{\circ}$ analyzers located before and after the tandem. Cycle times are 5-10 min. Intense stable isotope beams are attenuated by inserting a plate having many small holes into the beam following the injector magnet and are measured in the analyzer image cup. This cycling method has been used successfully at Rochester for over ten years.

For data acquisition from the ionization detector and automation of the isotope cycling sequence, we purchased three mid-sized VAX computers from Digital Equipment Corporation. A VAX 3400 acts as a central server under the VMS operating system. A real-time VAX 3400 communicates through a CAMAC interface to the apparatus under the ELN operating system. A VAXstation 3100 workstation provides a user interface under the X-windows standard. We are using the URSULA data acquisition software developed for the AMS system at Rochester.

Our chemistry laboratory in the tandem building has been equipped and stocked. Samples already processed include water samples for ${ }^{36} \mathrm{Cl}$, soil samples for ${ }^{10} \mathrm{Be}$ and iron meteorite samples for ${ }^{36} \mathrm{Cl}$. Processing has begun on terrestrial rocks for surface exposure dating using ${ }^{10} \mathrm{Be},{ }^{36} \mathrm{Cl}$ and ${ }^{26} \mathrm{Al}$, and on various types of meteorites for these same three radionuclides.

\section{SCIENTIFIC RESEARCH}

\section{Calibration of Surface Exposure Dating Techniques - David Elmore, Linus Dep, Marek Zreda and Fred Phillips}

Determining the exposure age of surface rocks by measuring the buildup of cosmogenic radionuclides has become an important new tool for geomorphology. When ${ }^{36} \mathrm{Cl}$ is used for this, there is a large contribution to the production by thermal neutrons on ${ }^{35} \mathrm{Cl}$. Because of secondary neutron production and scattering within the rock, the flux of thermal neutrons increases a few centimeters below the surface and depends, along with composition, on the geometry of the rock. Thus, the neutron flux must be calculated for each sample collected, and the dependence on depth could be used to determine the erosion rate. We plan to calculate the neutron flux for various depths, rock geometries and compositions. We are testing predictions with ${ }^{36} \mathrm{Cl}$ profiles in rocks from Meteor Crater, Arizona.

\section{Bishop Creek Moraine Sequence - Marek Zreda, David Elmore and F. M. Phillips}

Glacial moraines contain a record of glacial periods, which can provide important information on paleoclimate. Bloody Canyon in the Sierra Nevada has five terminal moraine complexes, which were dated using buildup of cosmogenic ${ }^{36} \mathrm{Cl}$ by Phillips et al. (1990). We plan to continue this work at Bishop Creek, also in the Sierra Nevada, which has a number of advantages. We have identified 13 distinct end moraines at Bishop Creek, which we estimate span the period from mid-Pleistocene to about $15 \mathrm{ka}$ BP. Most older moraines in the Sierra Nevada show few or no identifiable original surfaces on boulders. The Bishop Creek moraines are at unusually low elevation and are apparently in a deep rain shadow "pocket." Thus, they are exceptionally well preserved, and we can find at least a few glacially polished surfaces on even the older moraines. Because of this exceptional surface preservation, we can rule out erosion, and can compare varnish dating methods with cosmogenic ${ }^{36} \mathrm{Cl}$ on the same boulders, which is possible in very few other places. We are starting with about five ${ }^{36} \mathrm{Cl}$ measurements per moraine. We will then choose the oldest and measure ${ }^{10} \mathrm{Be}$ and ${ }^{26} \mathrm{Al}$ in quartz grains. We will also measure depth profiles of ${ }^{36} \mathrm{Cl}$ if they turn out to be useful indicators of erosion as described above. 


\section{Chlorine-36 in Indiana Groundwater - Steven Fritz and Stephan Vogt}

We have embarked on a research project involving dating groundwater recharge events with ${ }^{36} \mathrm{Cl}$. The project consists of sampling shallow wells having a high concentration of tritium. The tritium contents of these wells lie between 55 and 90 tritium units (TU), but we do not know which side of the tritium bomb spike (having its peak in 1963) they represent. Because the zenith of ${ }^{36} \mathrm{Cl}$ activity in rainfall occurred in 1957, a comparison of these well waters ${ }^{36} \mathrm{Cl}$ content with their tritium values should determine whether they were recharged before or after 1963 . Analyses of these waters' ${ }^{36} \mathrm{Cl}$ contents gave exceedingly high ${ }^{36} \mathrm{Cl}$ activities - much higher than can be explained by the bomb pulse. Accordingly, more extensive sampling of well waters is presently being performed for additional ${ }^{36} \mathrm{Cl}$ activities.

Canyon Diablo Meteorite Depth Profiles - Michael Lipschutz, Stephan Vogt, Ed Michlovich and Michael Shortreed

We have begun to determine the production depth profile for various cosmogenic radionuclides (including ${ }^{36} \mathrm{Cl}$ and ${ }^{41} \mathrm{Ca}$, which should be especially interesting because they are produced by neutron capture as well as spallation) in the Canyon Diablo meteorite. This meteorite is especially good for such a study because it is uniquely large (so that the production rate variation with depth is maximized) and chemically simple, with individual sample sizes being more than adequate. We have begun this study by chemically processing a number of the Canyon Diablo specimens for which shock-loading and pre-atmospheric depth in the meteoroid (from measurement of cosmogenic mobile gases) were determined by Heymann et al. (1966).

\section{Beryllium-10 in Indiana Soils - Don Franzmeier}

To maintain a productive agriculture, we must protect the quality of our soil resource. In the United States, selection of agricultural practices depends, to some extent, on the tolerable soil loss (T). A certain rate of soil loss from erosion can be tolerated if it does not exceed the rate at which soil (the root zone) is formed from geologic material. For many soils in the Midwest, this is about 4 tons acre $\mathrm{yr}^{-1}$ or about $0.7 \mathrm{~mm} \mathrm{yr}^{-1}$. In recent years, the US government has said, in effect, that farmers who use methods that result in erosion more than $T$ will not be eligible for subsidies. We have developed fairly sophisticated models to predict soil erosion, but we compare those predictions with $\mathrm{T}$ values based on little experimental information. To establish better $\mathrm{T}$ values requires knowledge of the age of landscape surfaces and the age of soils. Studies using ${ }^{10} \mathrm{Be}$ will contribute to this knowledge. We plan to determine the ${ }^{10} \mathrm{Be}$ content of soil profiles on stable landscape surfaces in forest vegetation in Indiana. One is a Wisconsin-age surface (ca. $20 \mathrm{ka}$ ) in central Indiana. The other is in southern Indiana where Wisconsin loess covers a paleosol formed during Sangamon time ( $c a .125 \mathrm{ka}$ ). These sites will serve as benchmarks to compare with other soils on less stable (eroded) landscape positions. In order to interpret ${ }^{10} \mathrm{Be}$ studies, we need to know where beryllium, deposited with rain, resides in soils. For example, it might occur as: 1) exchangeable cations; 2) free oxides (e.g., similar to goethite, hematite, etc.); or 3) part of a silicate mineral structure. These components can be separated by specific extracting solutions, e.g., $1 \mathrm{M}$ ammonium acetate for component 1 and reducing and complexing agents such as sodium dithionite and citrate for component 2 .

Atmospheric Transport and Deposition of ${ }^{7} \mathrm{Be},{ }^{10} \mathrm{Be}$, and ${ }^{36} \mathrm{Cl}-$ Grant Petty, Stephan Vogt, David Knies and David Elmore

We plan to utilize AMS in conjunction with auxiliary physical, chemical and meteorological measurements relevant to precipitation and aerosol physics, to investigate atmospheric concen- 
trations and surface deposition rates of the cosmogenic radionuclides ${ }^{36} \mathrm{Cl},{ }^{10} \mathrm{Be}$ and ${ }^{7} \mathrm{Be}$. Particular emphasis will be placed on: 1) documenting and understanding variability in the ${ }^{36} \mathrm{Cl} /{ }^{10} \mathrm{Be}$ ratio, because such variability could shed light on important differences in the atmospheric transport and scavenging of the two elements; and 2) relating variability in overall concentrations of each isotope and in the ${ }^{7} \mathrm{Be} /{ }^{10} \mathrm{Be}$ ratio to identifiable meteorological factors, such as episodes of stratospheric air injection into the troposphere, air mass histories and trajectories and precipitation phase and character.

\section{ACKNOWLEDGMENTS}

Dean of Science, Kenneth Kliewer, led the initiative for the AMS program and continues to play a major leadership role in the facility. Major support has been provided by department heads, Arnold Tubis (Physics), Harry Morrison (Chemistry) and Ernie Agee (Earth and Atmospheric Sciences). PRIME Lab is supported by the National Science Foundation under grant EAR-8916667.

\section{REFERENCES}

Phillips, F. M., Zreda, M. G., Smith, S. S., Elmore, D., Kubik, P. W. and Sharma, P. 1990 Cosmogenic chlorine-36 chronology for glacial deposits at Bloody Canyon, Eastern Sierra Nevada. Science 248: 15291532.
Heymann, D., Lipschutz, M. E., Nielsen, B. and Anders, E. 1966 Canyon Diablo Meteorite: Metallographic and mass spectrometric study of 56 fragments. Journal of Geophysical Research 71: 619-641. 